\title{
Response to high frequency jet ventilation may predict the need for extracorporeal membrane oxygenation
}

\author{
D.L. Stewart, T.V. Dela Cruz, S.D. Duncan, L.N. Cook
}

Response to high frequency jet ventilation may predict the need for extracorporeal membrane oxygenation. D.L. Stewart, T.V. Dela Cruz, S.D. Duncan, L.N. Cook. @ERS Journals Ltd 1996.

ABSTRACT: The aim of this study was to determine predictors of response whilst using high frequency jet ventilation (HFJV) for infants in intractable respiratory failure, in order to avoid the utilization of extracorporeal membrane oxygenation (ECMO).

We reviewed patient demographics, ventilator parameters, blood gas values, length of oxygen therapy and use of surfactant and outcome, in infants given a $4 \mathrm{~h}$ trial of HFJV as the minimum to eliminate those infants where HFJV is used as a bridge to ECMO. The study was carried out in the neonatal intensive care nursery at Kosair Children's Hospital in Louisville, Kentucky, which provides high frequency ventilation and ECMO. Thirty infants who were eligible for ECMO and who met the study criteria were divided into two groups based upon response to HFJV.

Twenty two infants responded to HFJV and eight nonresponders required ECMO after a trial of HFJV. Infants responding during HFJV demonstrated a significant decrease in oxygenation index without an escalation of mean airway pressure within $4 \mathrm{~h}$ after the initiation of HFJV. These infants had lower birth weights and an increased incidence of respiratory distress syndrome. No statistical differences were found in length of ventilation, days of oxygen therapy or duration of HFJV between the groups.

Infants in intractable respiratory failure, who are eligible for extracorporeal membrane oxygenation, should receive a trial of high frequency jet ventilation, especially if the cause is respiratory distress syndrome unresponsive to surfactant therapy. During high frequency jet ventilation, the oxygenation index and mean airway pressure should be monitored serially, since they may predict the need for extracorporeal membrane oxygenation.

Eur Respir J., 1996, 9, 1257-1260.

Recent reports have shown that infants with severe respiratory failure unresponsive to conventional therapies and meeting the traditional qualifying criteria for extracorporeal membrane oxygenation (ECMO) may respond when placed on high frequency ventilation without requiring ECMO [1-3]. BAUMGART et al. [3] demonstrated that infants in intractable respiratory failure who are candidates for ECMO can sometimes be rescued by high frequency jet ventilation (HFJV) if a rapid decrease in the oxygenation index (OI) is seen at 1 and $6 \mathrm{~h}$ after the initiation of HFJV, thus avoiding ECMO.

With the increasing use of HFJV, it is important to identify institutional criteria that might distinguish responders whilst using HFJV from those that will require ECMO after failing a trial of HFJV. We, therefore, reviewed our recent experience with HFJV: 1) to establish that HFJV treatment can (in certain infants) obviate the need for ECMO; and 2) to find early predictors that define success or failure with HFJV.

\section{Methods}

From March 1990 until August 1992, 1,920 infants were admitted to the neonatal intensive care unit (NICU)
Dept of Pediatrics, University of Louisville School of Medicine, Louisville, KY, USA.

Correspondence: D.L. Stewart,

Dept of Pediatrics

Division of Neonatology

University of Louisville School of Medicine

Louisville

KY 40292

USA

Keywords:

Extracorporeal membrane oxygenation high frequency ventilation

Received: July 61995

Accepted after revision February 61996 at Kosair Children's Hospital in Louisville, KY, USA. One hundred and fifteen infants were treated with (HFJV) (Life Pulse; Bunnell Inc., Salt Lake City, UT, USA). Infants were eligible for the study if they met the following criteria: 1) mean airway pressure $(P$ aw $) \geq 15 \mathrm{cmH}_{2} \mathrm{O}$ on conventional ventilation prior to HFJV; 2) minimum of $4 \mathrm{~h}$ of HFJV (to give an adequate time trial where HFJV was not being temporarily used as a bridge to ECMO); 3) no congenital heart disease other than a patent ductus arteriosus; and 4) no contraindications to ECMO. Institutional criteria for ECMO were: 1) birth weight $>2,000 \mathrm{~g}$; 2) gestational age $>33$ weeks; 3) no major congenital anomalies; 4) absence of an intraventricular haemorrhage (IVH) >grade 1 by Papile's classification; 5) absence of uncontrollable bleeding or irreversible coagulopathy; 6) no chronic lung changes from prolonged ventilation; and 7) arterial oxygen tension $\left(\mathrm{Pa}, \mathrm{O}_{2}\right) 6.7$ $\mathrm{kPa}(<50 \mathrm{mmHg})$ for $4 \mathrm{~h}$ despite maximum medical therapy or acute deterioration.

Thirty infants met the study criteria. Eighty five infants were excluded for the following reasons: 1) $<33$ weeks gestation (26); 2) birth weight $<2,000$ grams (5); 3) IVH $>$ grade $1(2)$; 4) congenital anomaly (5); 5) congenital heart disease $(5)$; 6) paediatric patients $(4)$; 7) $P$ aw $<15$ 
$\left.\mathrm{cmH}_{2} \mathrm{O}(19) ; 8\right) \mathrm{HFJV}<4$ h requiring ECMO secondary to acute deterioration with $\mathrm{Pa}, \mathrm{O}_{2} 6.7 \mathrm{kPa}(<50 \mathrm{mmHg})$ on assisted ventilation or uncontrollable hypotension (19).

The data reviewed included patient demographics, conventional ventilator and HFJV settings, arterial blood gas values, length of ventilation, duration of oxygen therapy and outcome. Mean airway pressure values were measured at the distal trachea through a triple lumen endotracheal tube (Hi-Lo Tube; Mallinckrodt Inc., St. Louis, MO, USA) on HFJV and through a standard endotracheal tube on conventional ventilation. These values were calculated from the airway pressure measured by the HFJV at the distal trachea and displayed on the face panel of the ventilator. The oxygenation index (OI) was calculated as follows:

$$
\mathrm{OI}=\frac{P \mathrm{aw} \times F_{\mathrm{I}, \mathrm{O}_{2}} \times 100}{P{\mathrm{a}, \mathrm{O}_{2}}}
$$

Both groups (responders and nonresponders) who failed to stabilize with conventional mechanical ventilation as indicated by a $\bar{P}$ aw $\geq 15 \mathrm{cmH}_{2} \mathrm{O}$ were placed on HFJV in a similar manner. The $\bar{P}$ aw measured on conventional ventilation was used as the starting $\bar{P}$ aw on HFJV, and the level was increased as needed to ensure adequate oxygenation, as indicated by arterial blood gas values. A frequency of $7 \mathrm{~Hz}$ and an inspiratory time of $0.02 \mathrm{~s}$ were used, as recommended by the manufacturer of the Bunnell Jet Ventilator, and these levels were not varied.

In this study, responders are defined as those infants who remained on HFJV with acceptable arterial blood gas values target blood gas values: $\mathrm{pH} 7.25-7.55 ; \mathrm{Pa}_{\mathrm{a}} \mathrm{O}_{2}$ $\geq 6.7 \mathrm{kPa}(50 \mathrm{mmHg})$; arterial carbon dioxide tension $\left(P \mathrm{a}, \mathrm{CO}_{2}\right) \leq 8.0 \mathrm{kPa}(60 \mathrm{mmHg})$ after failing conventional mechanical ventilation. Nonresponders are those infants who failed conventional mechanical ventilation and HFJV, subsequently requiring placement on ECMO. Failure of HFJV was defined as continued lability in oxygenation despite escalation of HFJV support.

Infants were seen in the follow-up clinic at adjusted chronological ages of 6 months, 1 and 2 yrs. Physical examinations were performed on all patients by a neonatologist or neonatal fellow, and developmental assessments were made by a single psychologist at each visit. Testing was carried out using the Bayley Scales of Infant Development.

Statistical analysis of the data was performed using the Student's t-test and Fisher's exact test.

Table 1. - Primary diagnosis

\begin{tabular}{lcc}
\hline & $\begin{array}{c}\text { Responders } \\
(\mathrm{n}=22)\end{array}$ & $\begin{array}{c}\text { Nonresponders* } \\
(\mathrm{n}=8)\end{array}$ \\
\hline RDS & 9 & 1 \\
Sepsis & 4 & 3 \\
PPHN & 4 & 2 \\
Amniotic-fluid-aspiration & 3 & 1 \\
MAS & 2 & 1
\end{tabular}

*: there were no significant differences in primary diagnosis between the two groups. RDS: respiratory distress syndrome; PPHN: persistent pulmonary hypertension of the newborn; MAS: meconium aspiration syndrome.
Table 2. - Patient characteristics and ventilatory support

\begin{tabular}{|c|c|c|}
\hline & $\begin{array}{l}\text { Responders } \\
\quad(n=22)\end{array}$ & $\begin{array}{c}\text { Nonresponders } \\
\quad(\mathrm{n}=8)\end{array}$ \\
\hline Gestational age weeks & $38(2)$ & $39(2)$ \\
\hline Birth weight $\mathrm{kg}$ & $3.2(0.6)$ & $3.6(0.4)^{*}$ \\
\hline Gender $\mathrm{M} / \mathrm{F}$ & $19 / 3$ & $6 / 2$ \\
\hline $\begin{array}{l}\text { Median Apgar score } \\
\text { at } 1 \mathrm{~min}\end{array}$ & 7 & 9 \\
\hline $\begin{array}{l}\text { Median Apgar score } \\
\text { at } 5 \text { min }\end{array}$ & 8 & 9 \\
\hline Survival & 22 & $7^{\dagger}$ \\
\hline Ventilation days & $10.5(8.8)$ & $10.5(4.2)$ \\
\hline Oxygen support days & $11.5(6.3)$ & $15.9(3.8)$ \\
\hline HFJV h & $53.3(31.0)$ & $37.1(42.3)$ \\
\hline $\begin{array}{l}\text { Infants with } \\
\text { an OI } \geq 40 \mathrm{n}\end{array}$ & 9 & 5 \\
\hline
\end{tabular}

\section{Results}

Thirty infants met study criteria. They were divided into two groups based on their response to HFJV. Twenty two infants designated as responders were rescued utilizing HFJV and did not require placement on ECMO. Eight infants did not respond to HFJV, subsequently requiring ECMO, and were designated as nonresponders. The infant's primary diagnoses are shown in table 1 and patient characteristics are shown in table 2.

The most common diagnosis was respiratory distress syndrome (RDS). Nine out of 10 infants with RDS responded to HFJV after failing conventional ventilation. No statistical differences were found in gestational age but responders weighed less than nonresponders (3.15 vs $3.64 \mathrm{~kg}$; $\mathrm{p}<0.015)$. Seventy eight percent of responders with RDS received surfactant therapy (Exosurf Neonatal ${ }^{\circledR}$, Burroughs Wellcome Co., Research Triangle Park, NC, USA) based on the clinical judgement of the individual attending neonatologist. The average number of doses of surfactant for responders was two (range $1-4)$ doses. Two infants with RDS in the responder group received all surfactant doses on HFJV. One infant in the nonresponder group with persistent pulmonary hypertension of the newborn received surfactant. The length of ventilatory support was not different between the groups and none of the infants developed chronic lung disease defined as an oxygen requirement at 30 days of age. All infants who responded to HFJV survived. One infant in the nonresponder group died from herpes simplex sepsis.

The $P$ aw was measured from $1 \mathrm{~h}$ prior to HFJV to $4 \mathrm{~h}$ after the initiation of HFJV. In the nonresponder group, the $\bar{P}$ aw continued to steadily increase during the $4 \mathrm{~h}$ of HFJV compared to responders. This increase was statistically significant after $4 \mathrm{~h}$ of HFJV in the nonresponders but not significant in the responders. The OI was calculated for the same time-period as the measured $P$ aw. Responders demonstrated a rapid decrease in OI that was statistically significant at 2 and $3 \mathrm{~h}$ compared to the $1 \mathrm{~h}$ pre-HFJV OI. The OI decreased in the nonresponders but this_was not statistically significant and required a higher $\bar{P}_{\text {aw }}$. Table 3 summarizes these results. 
Table 3. - Mean airway pressures and oxygenation index (OI) prior to and during HFJV

\begin{tabular}{|c|c|c|c|c|}
\hline & \multicolumn{2}{|c|}{ Responders } & \multicolumn{2}{|c|}{ Nonresponders } \\
\hline & $P$ aw & OI & Paw & OI \\
\hline $1 \mathrm{~h}$ pre-HFJV & $15.5(3.8)$ & 30.9 (15.7) & $16.8(1.3)$ & $43.8(12.1)$ \\
\hline HFJV & 16.9 (1.9) & $32.1(17.4)$ & $17.3(1.1)$ & $34.1(10.9)$ \\
\hline$+1 \mathrm{~h}$ & $16.6(3.2)$ & 19.4 (12.7) & $18.0(1.8)$ & $33.3(15.1)$ \\
\hline$+2 \mathrm{~h}$ & $16.8(3.0)$ & $14.9(9.2)^{*}$ & $18.7(2.1)$ & 24.9 (12.9) \\
\hline$+3 \mathrm{~h}$ & $17.1(2.6)$ & $12.6(6.5)^{\dagger}$ & 18.7 (1.7) & $26.2(13.4)$ \\
\hline$+4 \mathrm{~h}$ & $17.0(2.4)$ & $10.7(5.2)$ & $19.3(2.4)^{\#}$ & $17.6(13.4)$ \\
\hline
\end{tabular}

Values are presented as mean, and SD in parenthesis. ${ }^{*}{ }^{\dagger},{ }^{*}: \mathrm{p}<0.044,0.032,0.016$ respectively compared to $1 \mathrm{~h}$ pre HFJV. For further abbreviations see legend to table 2.

Table 4. - Bayley scales of infant development

\begin{tabular}{lcc}
\hline & $\begin{array}{c}\text { Responders } \\
(\mathrm{n}=11)\end{array}$ & $\begin{array}{c}\text { Nonresponders* } \\
(\mathrm{n}=6)\end{array}$ \\
\hline Age of test months & $13.3 \pm 7.4$ & $10.3 \pm 3.1$ \\
Bayley & & \\
$\quad$ MDI & $121.2 \pm 15.2$ & $108.2 \pm 17.6$ \\
PDI & $105.7 \pm 11.1$ & $102.3 \pm 14.4$ \\
\hline
\end{tabular}

Values are presented as mean \pm SD. MDI: Mental Development Index; PDI: Psychomotor Development Index. *: there was no statistically significant differences between the two groups.

Seventeen (6 nonresponders and 11 responders) of the 29 surviving infants were seen in the neurodevelopmental follow-up clinic. Twelve infants were lost to follow-up. The reasons included: relocation (2); and poor compliance (10). Bayley Scales of Infant Development were performed by a single psychologist (table 4). Infants were evaluated at 6-25 months of age. Mean mental and psychomotor developmental indices were similar for the two groups. One infant in the nonresponders had Bayley scores outside the normal range. The Bayley scores for this infant at $1 \mathrm{yr}$ of age were borderline normal both for psychomotor and mental indices. Physical examination demonstrated mild left-sided weakness despite a normal computed tomography of the head. Hearing evaluation at the time of discharge or in the follow-up clinic using either the modified or full auditory brainstem evoked response was normal in all 17 infants (6 nonresponders and 11 responders) who were tested.

\section{Discussion}

Since the introduction of HFJV and ECMO as rescue therapies for infants in intractable respiratory failure, HFJV is being used in an increasing number of neonatal intensive care units in ECMO-eligible infants, when conventional therapies have failed. However, criteria for ECMO have not included a trial of HFJV. Furthermore, ECMO is not universally available. This presents a dilemma with respect to optimal management and timely referral for ECMO.

BAUMGART et al. [3] reported that ECMO-eligible infants in respiratory failure responded to HFJV if their OI decreased from 30 to 19 after $1 \mathrm{~h}$ of HFJV and from 30 to 15 after $6 \mathrm{~h}$ of HFJV. Also, infants with an OI $\geq 40$ with meconium aspiration syndrome (MAS) or persistent pulmonary hypertension of the newborn (PPHN) did not respond as well to HFJV as infants with RDS or pneumonia. They suggested earlier institution of ECMO in nonresponders because mortality is high in these infants. MARSH et al. [4] reported that $75 \%$ of their infants with a $\bar{P}$ aw $\geq 15 \mathrm{cmH}_{2} \mathrm{O}$ and an $\mathrm{OI} \geq 40$ required ECMO despite an initial response to HFJV. Their study suggested that non-ECMO centres with HFJV capabilities should consider early referral to an ECMO centre for these infants.

In this study, ECMO-eligible infants who responded to HFJV demonstrated a rapid decrease in OI after $1 \mathrm{~h}$ of HFJV. The decrease in OI continued and became significant after $2 \mathrm{~h}$ of HFJV, without a significant change in $\bar{P}$ aw during the $4 \mathrm{~h}$ of HFJV, when compared to infants who subsequently required ECMO after a trial of HFJV. At $4 \mathrm{~h}$ of HFJV, infants who needed ECMO required an increase in their $\bar{P}$ aw to maintain oxygenation. This increase in $\bar{P}$ aw proved statistically significant. However, the OIs in both groups continued to decrease but was not statistically significant at this point. A nonsignificant decrease in OIs at $4 \mathrm{~h}$ was noted in the nonresponder group. These infants initially responded somewhat to HFJV in the $4 \mathrm{~h}$ after placement, but deteriorated after 12-24 $\mathrm{h}$ on HFJV requiring ECMO. All infants who responded to HFJV and continued to do well on HFJV failed to meet ECMO criteria during their HFJV course. Twenty five percent of our infants with a $\bar{P}$ aw $\geq 15 \mathrm{cmH}_{2} \mathrm{O}$ and OI $\geq 40$ needed ECMO, which is a much smaller proportion than that reported by MARSH et al. [4]. Two out of six infants meeting these criteria, with the diagnosis of PPHN or aspiration syndromes, required ECMO which is in accordance with the findings of BAUMGART et al. [3].

High frequency ventilation has been shown to be an effective therapy in treating RDS [3,5-8]. CARLO et al. [5] reported adequate gas exchange using HFJV at lower $\bar{P}$ aw than conventional ventilation without an increase in side-effects. ClARK et al. [6] demonstrated a decreased incidence of chronic lung disease using high frequency oscillatory ventilation. None of the patients in the study of ClARK et al. [6] study received surfactant therapy. Both reports were in infants less than $1,800 \mathrm{~g}$ and not eligible for ECMO in most centres. This study shows that $90 \%$ of ECMO-eligible infants with the primary diagnosis of RDS responded to HFJV as a rescue therapy. Six of nine patients received surfactant therapy during or prior to HFJV and did not require ECMO. Of nineteen infants placed on HFJV and not meeting study criteria but requiring ECMO, only one infant had RDS complicated by suspected sepsis since the twin sibling was diagnosed with group B streptococcal sepsis. No infant in our study developed chronic lung disease. This suggests that the use of HFJV and surfactant therapy is effective in treating RDS and avoiding ECMO. However, the primary diagnosis of RDS may be a confounding 
variable in this study, since $40 \%$ of responders and $13 \%$ of nonresponders had this diagnosis. This difference in response between the two groups may be related to having RDS, but a significant difference still exists with other diagnoses if RDS is excluded. In contrast to RDS, ECMO should be considered earlier in infants with sepsis, since they demonstrated the poorest response to HFJV. A previous study from our institution involving infants with group B streptococcal disease suggested that these infants are unpredictable and should be considered for early referral if acidosis and hypotension develop [9].

High frequency jet ventilation is used in our institution in an attempt to stabilize the infant while preparations are made for the initiation of ECMO. We chose $4 \mathrm{~h}$ on HFJV as a study criterion in order to eliminate those infants who were placed on HFJV for stabilization prior to ECMO, since $88 \%$ of nonresponders and $82 \%$ of responders were transported to our hospital for further respiratory management. This period of HFJV serves as a bridge to ECMO, since a majority of these infants that are transferred to our institution are very unstable. This was the reason why 19 infants who required HFJV were excluded from the study. The data suggest that this bridging period can also be used to discriminate between likely responders and nonresponders to HFJV.

In this study, we cannot state with certainty that ECMOeligible infants improved as a result of HFJV, since we did not have a control group of infants for comparison who remained on conventional mechanical ventilation. With today's current medical practice and ethics, it would be difficult to have a control group for comparison since high frequency ventilation and ECMO have been shown to benefit those infants who fail conventional therapies.

Limited information exists comparing the developmental outcome of ECMO-eligible infants responding to high frequency ventilation versus those requiring ECMO after HFJV. A prospective study comparing these two groups would be ideal but none has been reported in the literature so far. The difficulty of this type of study lies in the establishment of a control group, since it may be unethical to withhold ECMO treatment from any eligible infant after all forms of therapy have failed. In this study, the developmental outcome of all six nonresponders and 10 of the 11 responders seen in our follow-up clinic was normal. HendRICKS-MunOz et al. [10] found a high incidence of sensorineural hearing loss in infants with PPHN treated with hyperventilation. In this study, the hearing screens in all infants evaluated (6 nonresponders and 11 responders) were normal. The majority of these infants had PPHN complicating their primary disease process. No infant has manifested any hearing impairment upon subsequent visits. Although these results are encouraging, these infants are at risk for neuro-developmental problems. Previous studies [10-12] suggest that close follow-up, hearing evaluations and developmental testing into school age years are needed to detect any long-term sequelae.

A staged approach, as suggested by CARTER et al. [2] and BAUMGART et al. [3], can be used by intensive care units that do not provide ECMO. Infants in intractable respiratory failure who have failed conventional therapies can be treated with HFJV. Once HFJV is initiated, trends in the oxygenation index should be carefully followed.
As a centre that provides high frequency jet ventilation and extracorporeal membrane oxygenation, our experience demonstrates that high frequency jet ventilation is a viable alternative in infants, who are eligible for extracorporeal membrane oxygenation in intractable respiratory failure after failure of high frequency jet ventilation conventional therapies. Infants with respiratory distress syndrome have proved most likely to benefit from high frequency jet ventilation, especially if they have received surfactant therapy. Infants who respond will demonstrate a decrease in their oxygenation index without an escalation in mean airway pressure within $4 \mathrm{~h}$ after initiation of high frequency jet ventilation. After this trial period, a decision should be made regarding whether the infant should continue on high frequency jet ventilation or be transported to an extracorporeal membrane oxygenation centre. Thus, with serial monitoring, the mean airway pressure and oxygenation index serve as predictors of the impending need for extracorporeal membrane oxygenation in most infants.

\section{References}

1. Cornish JD, Gertsmann DR, Clark RH, Carter JM, Null DM Jr, deLemos RA. Extracorporeal membrane oxygenation and high-frequency oscillatory ventilation: potential therapeutic relationships. Crit Care Med 1987; 15: 831-834.

2. Carter JM, Gertsmann DR, Clark RH, et al. High-frequency oscillatory ventilation and extracorporeal membrane oxygenation for the treatment of acute neonatal respiratory failure. Pediatrics 1990; 85: 159-164.

3. Baumgart S, Hirschl RB, Butler SZ, Coburn CE, Spitzer AR. Diagnosis-related criteria in the consideration of extracorporeal membrane oxygenation in neonates previously treated with high-frequency jet ventilation. Pediatrics 1992; 89: 491-494.

4. Marsh TD, Rentz SH, Pai MS, Watson SW. Use of highfrequency jet ventilation in neonates with a mean airway pressure $\geq 15 \mathrm{cmH}_{2} \mathrm{O}$. 8th Annual Children's National Center ECMO Symposium. 1992 (Abstract).

5. Carlo WA, Chatburn RL, Martin RJ. Randomized trial of high-frequency jet ventilation versus conventional ventilation in respiratory distress syndrome. J Pediatr 1987; 110: 275-282.

6. Clark RH, Gertsmann DR, Null DM, deLemos RA. Prospective randomized comparison of high-frequency oscillatory and conventional ventilation in respiratory distress syndrome. Pediatrics 1992; 89: 5-9.

7. Clark RH, Gertsmann DR, Null DM, et al. Pulmonary interstitial emphysema treated by high-frequency oscillatory ventilation. Crit Care Med 1986; 14: 926-930.

8. Carlo WA, Beoglos A, Chatburn RL, Walsh MC, Martin RJ. High-frequency jet ventilation in neonatal pulmonary hypertension. Am J Dis Child 1989; 143: 233-238.

9. Hocker JR, Simpson PM, Rabalais GP, Stewart DL, Cook LN. Extracorporeal membrane oxygentation and earlyonset group B streptococcal sepsis. Pediatrics 1992; 89: $1-4$.

10. Hendricks-Munoz KD, Walton JP. Hearing loss in infants with persistent fetal circulation. Pediatrics 1988; 81: 650-656.

11. Bifano EM, Pfannenstiel A. Duration of hyperventilation and outcome in infants with persistent pulmonary hypertension. Pediatrics 1988; 81: 657-661.

12. Sell EJ, Gaines JA, Gluckman C, Williams E. Persistent fetal circulation: neurodevelopmental outcome. Am J Dis Child 1985; 139: 25-28. 